Article

\title{
Comparison of Whole-Tree Wood Property Maps for 13- and 22-Year-Old Loblolly Pine
}

\author{
Laurence Schimleck ${ }^{1, *}$, Finto Antony ${ }^{2}$, Christian Mora ${ }^{3}$ and Joseph Dahlen ${ }^{2}$ \\ 1 Department of Wood Science and Engineering, College of Forestry, Oregon State University, Corvallis, \\ OR 97331, USA \\ 2 Warnell School of Forestry and Natural Resources, University of Georgia, 180 E. Green Street, Athens, \\ GA 30602, USA; fintoa@gmail.com (F.A.); jdahlen@uga.edu (J.D.) \\ 3 Fibraconsult, Concepcion 4030000, Chile; crmora@fibraconsult.cl \\ * Correspondence: laurence.schimleck@oregonstate.edu; Tel.: +1-541-737-9171
}

Received: 20 April 2018; Accepted: 22 May 2018; Published: 24 May 2018

\begin{abstract}
Maps developed using Akima's interpolation method were used to compare patterns of within-tree variation for Pinus taeda L. (loblolly pine) wood properties in plantation-grown trees aged 13 and 22 years. Air-dry density, microfibril angle (MFA) and modulus of elasticity (MOE) maps represented the average of 18 sampled trees in each age class. Near infrared (NIR) spectroscopy models calibrated using SilviScan provided data for the analysis. Zones of high density, low MFA and high MOE wood increased markedly in size in maps of the older trees. The proportion of wood meeting the visually graded No. 1 (11 GPa) and No. 2 (9.7 GPa) MOE design values for southern pine lumber increased from 44 to $74 \%$ and from 58 to $83 \%$ respectively demonstrating the impact of age on end-product quality. Air-dry density increased from pith to bark at all heights but lacked a significant trend vertically, while radial and longitudinal trends were observed for MFA and MOE. Changes were consistent with the asymptotic progression of properties associated with full maturity in older trees.
\end{abstract}

Keywords: density; loblolly pine; microfibril angle; modulus of elasticity; near-infrared spectroscopy; Pinus taeda; within-tree variation; wood property maps

\section{Introduction}

The study of wood property variation within trees has been an important area of research for many years. A knowledge of how wood properties vary within trees is critical in developing an understanding of the effects of tree age on wood formation and for the optimal utilization of wood as a raw material. For common plantation species such as Pinus radiata D. Don (Monterey or radiata pine) and Pinus taeda L. (loblolly pine), general patterns of radial variation have long been recognized [1]; however, patterns of whole-tree variation are less well known. Research has generally been limited to studying pith-to-bark variation, either at breast height for trees sampled nondestructively, or at multiple heights for a small number of destructively sampled trees owing to the large number of samples that must be analyzed to achieve a reasonable level of resolution. This can be challenging given the costs of analyses [2-4]. Most studies of whole-tree variation have focused on density as it can be determined easily with X-ray densitometry, while studies of variability of wood chemistry related parameters such as cellulose and lignin are very limited [1].

The advent of the SilviScan instruments [2,5,6], which utilizes X-ray densitometry, X-ray diffractometry and image analysis to examine radial strips (dimensions: $2 \mathrm{~mm}$ thick tangentially, $7 \mathrm{~mm}$ longitudinally, radial length varies), has greatly reduced cost of analysis for microfibril angle (MFA), modulus of elasticity (MOE), and tracheid properties such as coarseness, radial and tangential 
diameter and wall thickness. In addition, SilviScan measurements are at high spatial resolution making studies of within-tree variation for these properties feasible [7,8]. Still, if a large number of trees or multiple heights per tree are to be analyzed, SilviScan determination of properties can be prohibitively costly. Near infrared (NIR) spectroscopy presents a complementary approach. Models based on NIR spectra from the surface of radial strips and SilviScan data have been reported with strong relationships $\left(R^{2}\right.$ consistently $\left.>0.8\right)$ for all properties except radial and tangential diameter $[9,10]$. These models successfully estimated radial variation for MFA [11], MOE [12] and density [13] in both P. radiata and P. taeda [14].

Recently, Schimleck et al. [15] described an approach for the development of multi-height, multi-tree NIR calibrations utilizing density, MFA and MOE data provided by SilviScan. Briefly, 411 pith-to-bark strips were obtained at multiple heights from 36 P. taeda trees. The trees were aged 13 and 22 years (18 trees were sampled at each age) and were from a half-sib progeny trial. NIR spectra were collected in $10 \mathrm{~mm}$ increments from all strips, and a subsample (representing multiple heights and radial positions), analyzed by SilviScan. Preliminary models, based on two-thirds of the data available and tested on the remaining third, provided statistics similar to those reported for calibrations based only on breast height samples. Final calibrations were based on all data available and then used to predict density, MFA and MOE in $10 \mathrm{~mm}$ increments for all strips. The authors noted that as the characterized samples were a subsample of all those available, the subsequent calibrations were directly applicable to all spectra collected from the 411 strips.

Mora and Schimleck [16] utilized this data and compared three spatial interpolation algorithms (Akima, universal kriging, and semiparametric regression) to develop maps for the 13-year-old trees to show within-tree variation for density and MFA. They also reviewed existing examples of wood property maps, noting that generally little detail was given about the methodology employed to obtain them, and concluded that lack of an adequate description of the methods used had limited their use. Hence their paper focused more on the interpolation techniques used to generate maps of within-tree variation than the wood property trends observed.

As noted by Burdon et al. [1], ring number from the pith is a key factor in determining wood properties and that wood properties depend heavily on stand age. Hence, maps depicting within-tree variation can be expected to change as stand age increases; however, these changes have not been explored in the literature. As the 13- and 22-year-old P. taeda samples utilized by Schimleck et al. [15] were from the same location and genetic trial they provide an excellent opportunity to explore changes in patterns of within-tree variation with time. Hence the aims of this study were:

1. to use Akima's interpolation method as employed by Mora and Schimleck [16] to develop maps showing the within-tree variation of density, MFA and MOE for P. taeda trees aged 13 and 22 years and;

2. to compare maps at the two different ages for the three properties.

\section{Materials and Methods}

\subsection{Sample Origin}

Two sets of eighteen P. taeda trees from a half-sib progeny trial planted at International Paper's (IP) Southlands facility were selected for sampling. The trees were aged 13 and 22 years respectively when sampled. The trees were a subsample of two larger populations and had been selected to encompass the range of cellulose, lignin and density variation as measured by IP. Selected trees were checked for fusiform rust pitch canker prior to sampling and trees with noticeable cankers were avoided. Selected trees were felled and samples removed for wood property and NIR analyses. Disks ( $25 \mathrm{~mm}$ thick) were taken at $1.5 \mathrm{~m}$ intervals along the stem of each tree, giving 9 to 13 disks per tree (number depended on tree height). A total of 191 disks were collected from trees aged 13 years, while 220 were obtained from the 22-year-old trees, giving a total of 411 disks. 


\subsection{Sample Preparation}

Pith-to-bark radial sections were cut from each disk using a bandsaw. Section dimensions were $12.5 \mathrm{~mm}$ longitudinally by $12.5 \mathrm{~mm}$ tangentially with the radial length corresponding to the length of the sample. Radial sections were gently dried, glued into core holders and cut using a twin-blade saw to give strips $2 \mathrm{~mm}$ thick (tangentially) using the methodology described in Jordan et al. [17].

\subsection{Near Infrared Spectroscopy}

Schimleck et al. [15] provide a detailed description of the methodology used to collect NIR spectra and develop predictive NIR models for air-dry density, MFA and MOE. To summarize, NIR spectra were collected in $10 \mathrm{~mm}$ increments from the radial-longitudinal face of each radial strip using a FOSS NIRSystems Inc Model 5000 scanning spectrometer. The total number of spectra collected was 2569 (1114 from 13-year-old trees and 1455 from trees aged 22 years). A subsample of 72 strips (two from each tree and representing different heights) were selected for determination of air-dry density, MFA and MOE by SilviScan [2-4]. SilviScan data was averaged over $10 \mathrm{~mm}$ sections (Figure 1) from pith to bark for correlation with the $10 \mathrm{~mm}$ NIR spectra data (477 in total, representing 179 and 298 spectra from trees aged 13 and 22 years respectively).

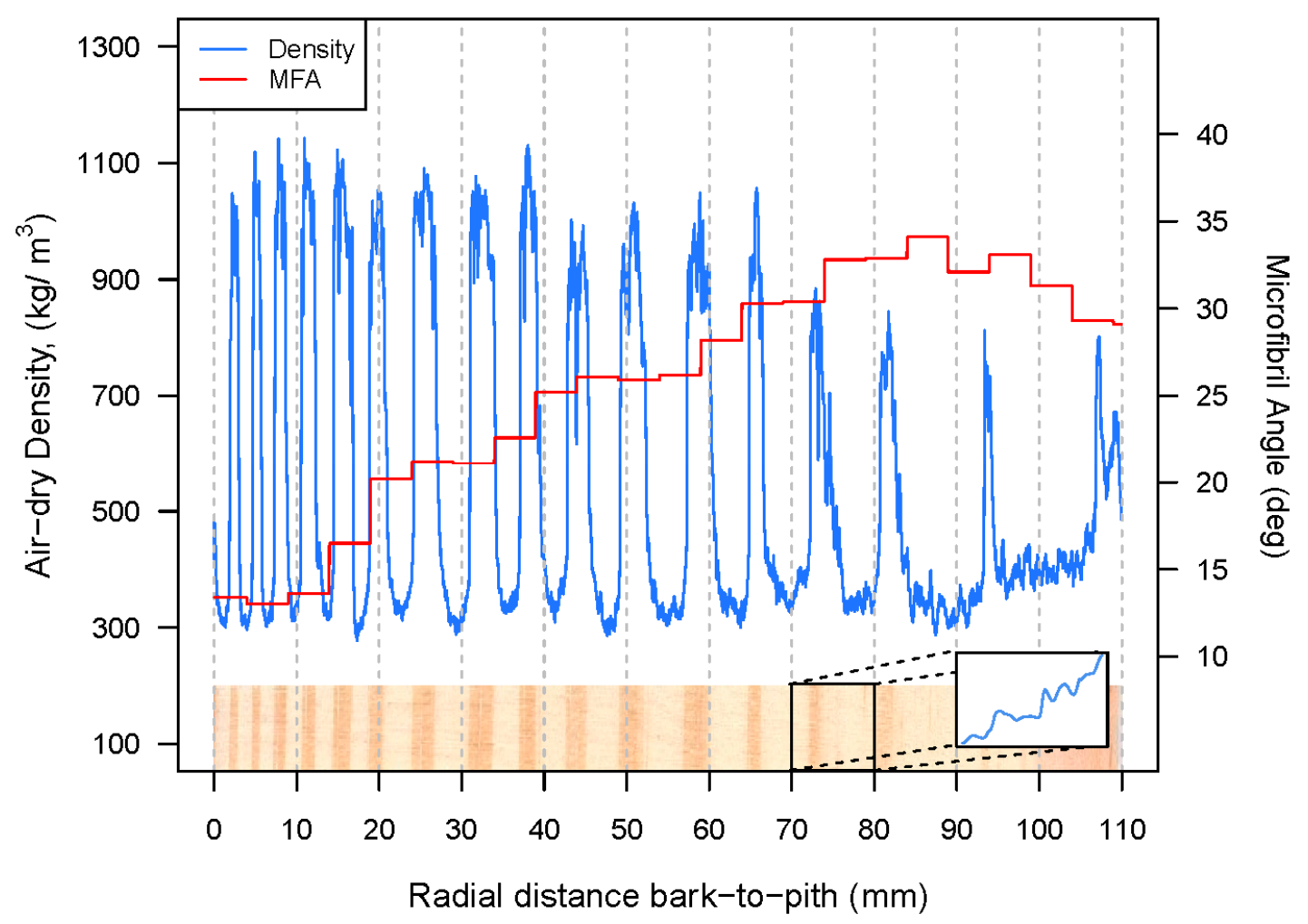

Figure 1. Air-dry density and MFA profiles for one sample measured at $10 \mathrm{~mm}$ resolution. The NIR spectrum of one $10 \mathrm{~mm}$ section is shown at the bottom of the plot.

\subsection{Multi-Height NIR-Based Wood Property Models}

Wood property calibrations based on the $10 \mathrm{~mm}$ NIR and SilviScan data were developed in two phases [15]. Our interest is in the phase two models, obtained using all 477 spectra, and representing both the 13- and 22-year-old samples and multiple sampling heights (Table 1). 
Table 1. Fit statistics for the multiple height P. taeda NIR calibrations developed for air-dry density, microfibril angle (MFA) and modulus of elasticity (MOE) using 477 NIR spectra. This table was originally published in Appita Journal [15] and is reproduced here with permission. SEC = standard error of calibration, SECV = standard error of cross validation and RPDC = ratio of performance to deviation, calculated as the ratio of the standard deviation of the reference data to the SECV.

\begin{tabular}{cccccc}
\hline Property & \# Factors & $\boldsymbol{R}^{\mathbf{2}}$ & SEC & SECV & RPDc \\
\hline Air-dry density & 5 & 0.88 & 41.8 & 43.0 & 2.8 \\
MFA & 10 & 0.91 & 2.5 & 2.6 & 3.2 \\
MOE & 10 & 0.93 & 1.2 & 1.3 & 3.6 \\
\hline
\end{tabular}

Each of the three properties had strong calibration statistics and compared well with those based on radial strips from a single height (breast height) for $P$. radiata [11-13] and $P$. taeda [14] despite representing many different heights. The models for air-dry density, MFA and MOE were then used to predict these properties in $10 \mathrm{~mm}$ increments for all 411 radial strips (2569 spectra in total).

\subsection{Data Analysis}

The NIR wood property calibrations were developed on the untreated spectral data using partial least squares regression and Unscrambler software (version 9.2, Camo AS, Oslo, Norway). The mean density, MFA, and MOE for each age was calculated by weighting the volume of each radial point compared to the overall volume and then summing each respective height. The volume weighted proportion of wood for each age that exceeded 650 and $550 \mathrm{~kg} / \mathrm{m}^{3}$ density, were below 30 and 20 degrees for MFA, and exceeded 11.0 and 9.7 GPa MOE were calculated. MOE limits were based on design values for visually graded No. 1 and No. 2 southern pine lumber [18].

The within-tree maps and data summaries were produced in the $\mathrm{R}$ statistical programing environment [19] with the RStudio interface [20], and the Akima [21], dplyr [22], fields [23], and lattice [24] packages.

\section{Results}

\subsection{Air-Dry Density}

Within-tree wood property maps for air-dry density are shown in Figure 2. The maps represent the average of 18 P. taeda trees aged 13 and 22 years, respectively.

The air-dry density map for the 13-year-old trees showed an increase in density from pith to bark at all heights. A vertical change in density was not observed which is in disagreement with Megraw [25] who observed lower density values at the same ring number with increasing height. However, the lack of a vertical trend may be due to the coarseness of the NIR data, or be masked here since the focus was not on annual ring properties but distance from the pith. As noted by Burdon et al. [1] change in density is directly related to percent latewood, tracheid wall thickness and lumen diameter. Typically, latewood density for $P$. taeda reaches a plateau at about age 12 while percent latewood takes longer (approximately 15 years) to reach its maximum [17]. Regional differences exist in the time taken to reach upper limits for both properties in the SE USA and can be related to variation in summer rainfall [17]. The asymptotic progression in properties can be related to maturation state, with $P$. radiata reaching full maturity (for most properties) after 10-12 years [1]. In P. taeda maturation processes are essentially the same; however, as noted by Burdon et al. [1] they occur "not at the same rate or in quite the same sequence of completion." 


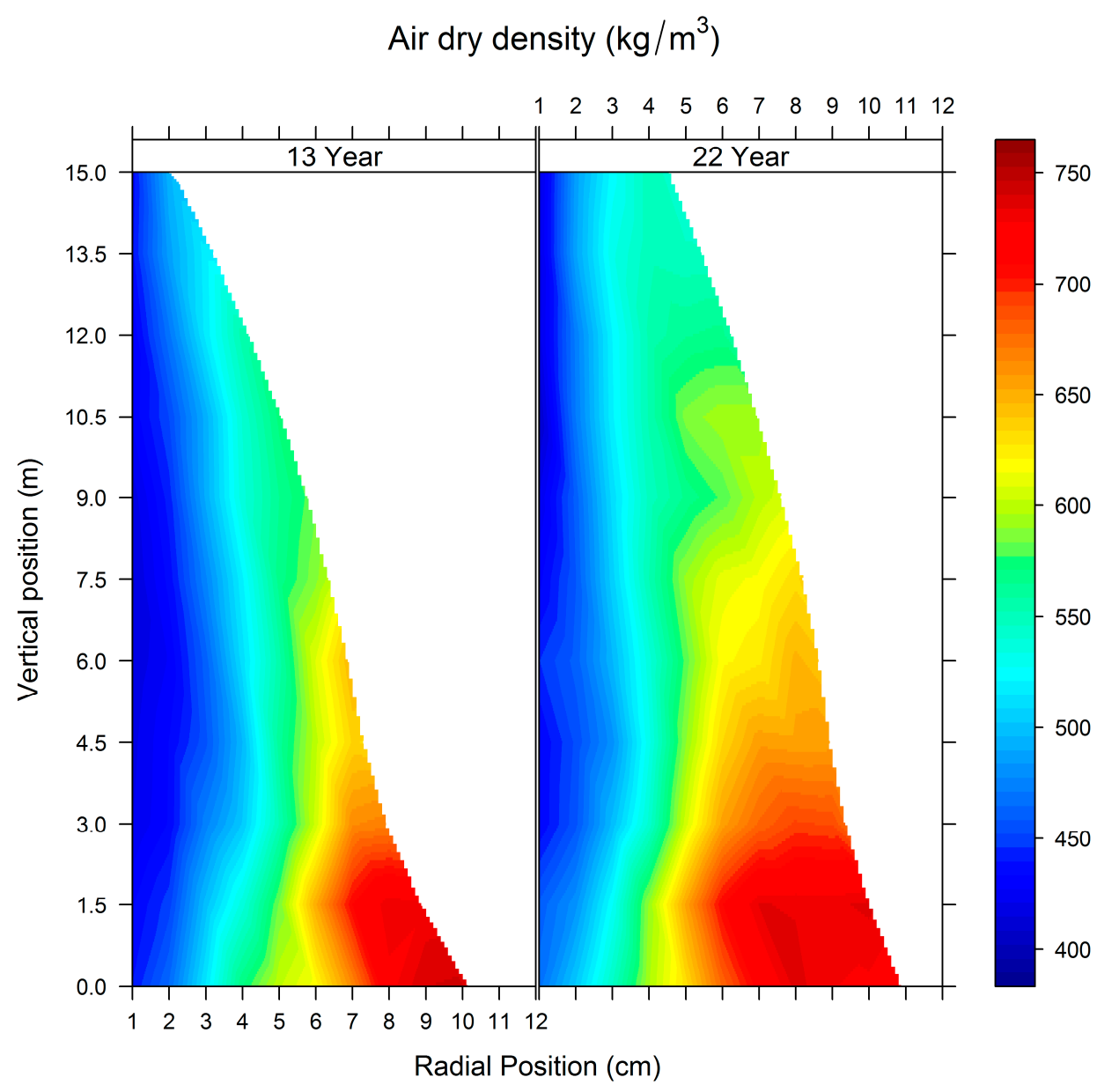

Figure 2. Maps showing within-tree variation of air-dry density $\left(\mathrm{kg} / \mathrm{m}^{3}\right)$ for P. taeda trees aged 13 and 22 years. Maps represent the average of 18 trees and were developed using Akima's interpolation method.

The density map for the 22-year-old trees shows a larger proportion of higher density wood at the base. A progression of increasing density with increasing height in the lower outside half of the stem is also apparent. Schimleck et al. [15] plotted density distributions for trees of both ages, and showed a clear shift to higher densities for the older trees. Average whole-tree densities for the 13and 22-year-old trees were 537.9 and $589.2 \mathrm{~kg} / \mathrm{m}^{3}$ respectively. These changes are consistent with maturation in wood properties in the older trees.

\subsection{Microfibril Angle (MFA)}

Within-tree wood property maps of MFA for P. taeda trees aged 13 and 22 years are shown in Figure 3. MFA maps showed patterns of variation different to those observed for air-dry density with both radial and longitudinal trends apparent. As noted by Burdon et al. [1] vertical changes in MFA are initially rapid trending to final values at relatively low heights. Such variation was apparent in both maps. A zone of high MFA wood (angles $>35^{\circ}$ ) was observed near the pith and below $1.0 \mathrm{~m}$ while the lowest MFA wood occurred near the periphery of the trunk and was centered around $4.5 \mathrm{~m}$. In the older trees the zone of low MFA wood (angles $<15^{\circ}$ ) was larger and extended from a height of $3 \mathrm{~m}$ to almost $11 \mathrm{~m}$. Average whole-tree MFA's for the 13- and 22-year-old trees were 20.9 and $17.5^{\circ}$, respectively [15], indicating the influence the zone of low MFA wood had on lowering whole-tree average MFA. 


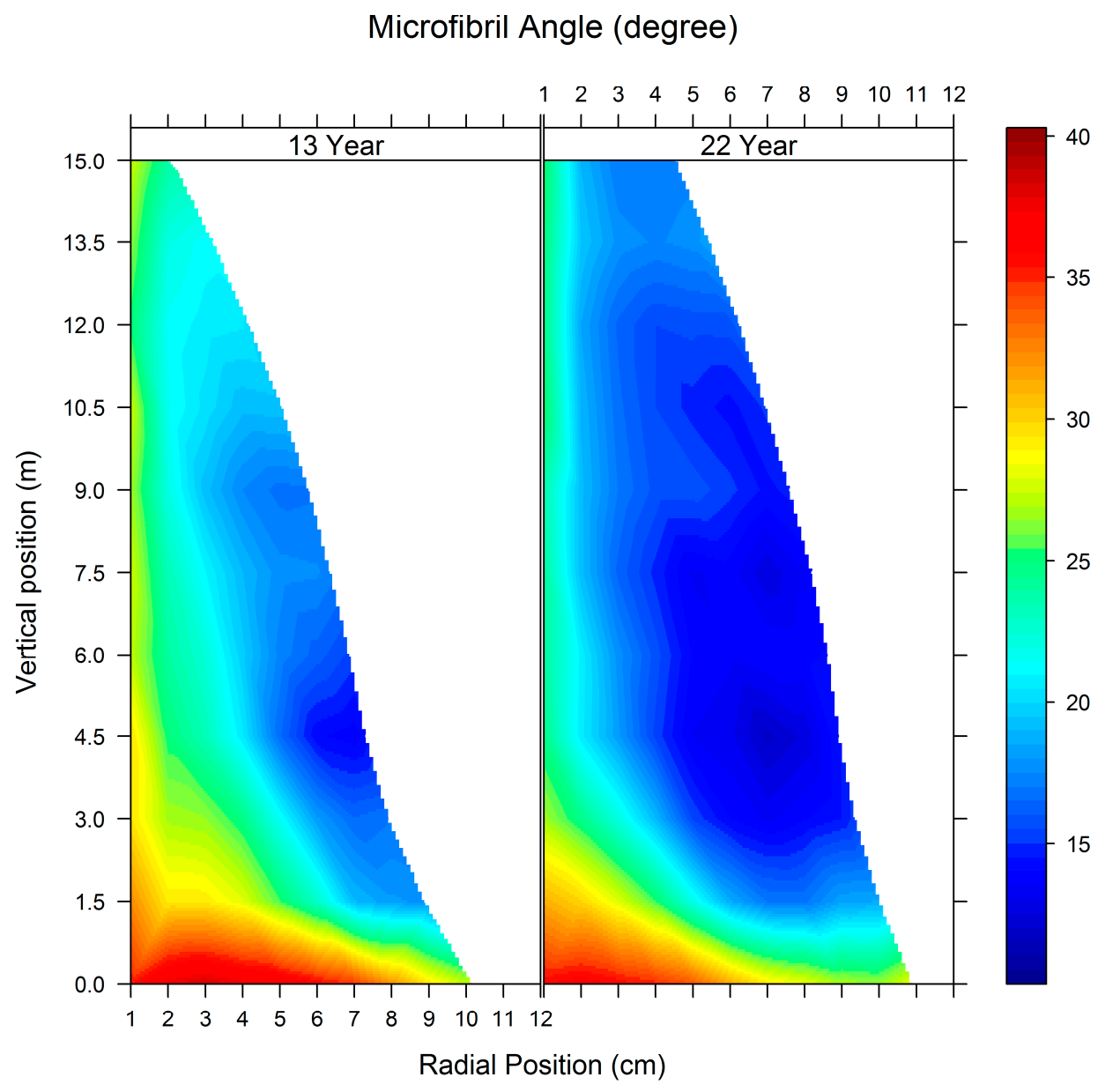

Figure 3. Maps showing within-tree variation of microfibril angle $\left(^{\circ}\right)$ for P. taeda trees aged 13 and 22 years. Maps represent the average of 18 trees and were developed using Akima's interpolation method.

The variability for MFA coincides with the description given by Jordan et al. [26] who modelled earlywood and latewood MFA in eighteen P. taeda trees that ranged in age from 21 to 24 years. In their study large MFA's were observed near the pith. With an increase in age MFA decreased rapidly to approximately 10 rings from the pith after which it continued to drop albeit at a much slower rate before stabilizing. The age at which MFA began to stabilize was when the trees were approximately 10 years old which is consistent with the age of full maturity described by Burdon et al. [1] and discussed in Section 3.1 for air-dry density.

The maps for MFA also demonstrate that wood properties are rapidly changing both vertically and radially in the lower part of the stem. The effect of superimposing these patterns of variation are modified pith-to-bark trends [1] near the base of the tree. Jordan et al. [26] observed this phenomenon for MFA and reported that decrease in MFA with ring position near the base occurs at a slower rate compared to higher in the tree. This results in higher MFA values for a given ring number from the pith at heights less than two meters (approximately) and a clear demarcation in plots of radial variation in MFA for samples from this zone compared to other heights. The maps of MFA show that high MFA near the base would result in high longitudinal shrinkage values that could potentially increase warp in lumber [27]. 


\subsection{Modulus of Elasticity (MOE)}

Figure 4 shows wood property maps of MOE for P. taeda trees aged 13 and 22 years respectively.

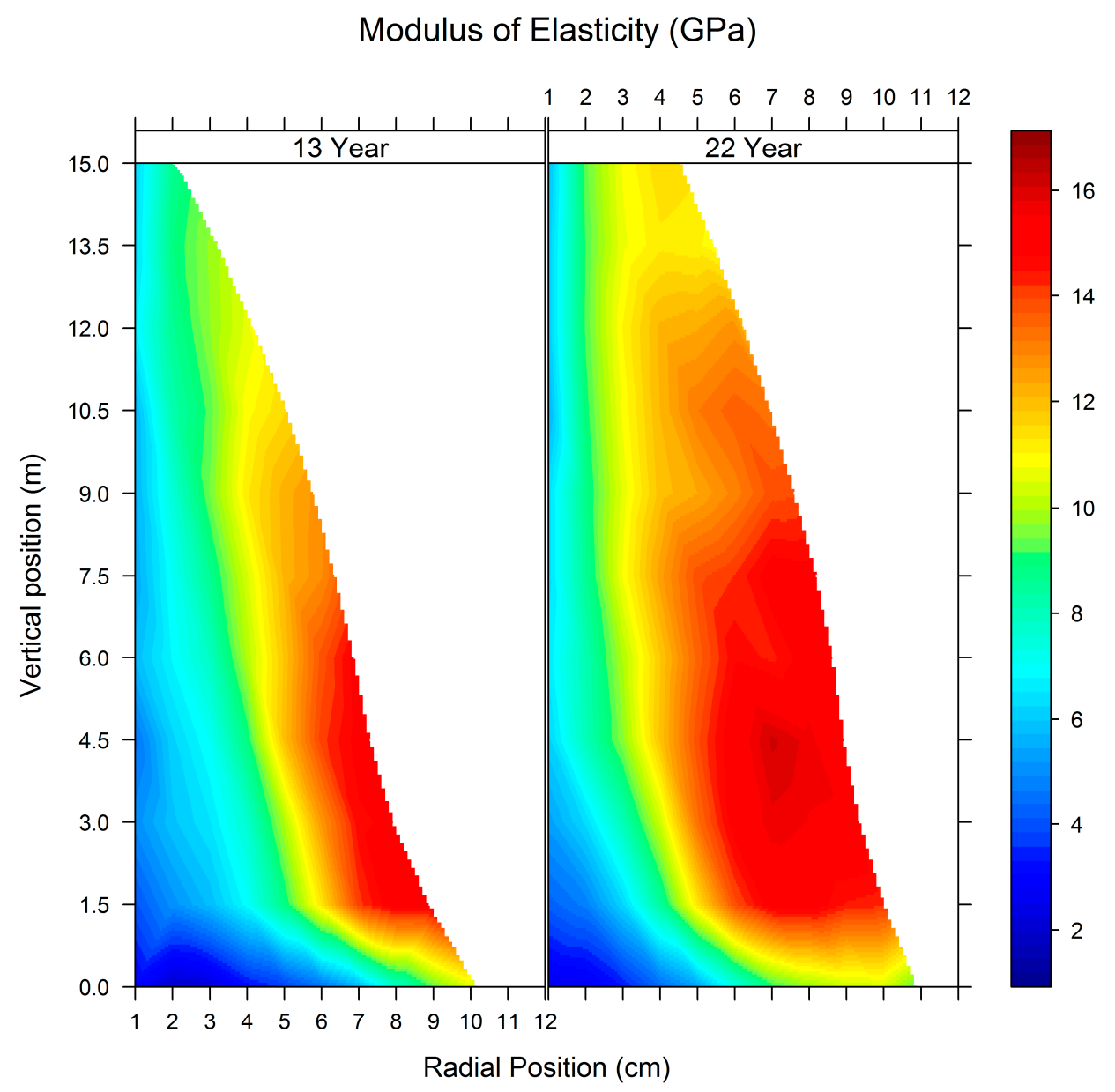

Figure 4. Maps showing within-tree variation of modulus of elasticity (GPa) for $P$. taeda trees aged 13 and 22 years. Maps represent the average of 18 trees and were developed using Akima's interpolation method.

The maps for MOE were similar to those for MFA with properties changing rapidly from pith to bark and with height at the base. A zone of very low stiffness wood $(<4 \mathrm{GPa})$ was observed near the pith, with the stiffest wood (>14 GPa) at the periphery of the stem. The zone of stiffest wood increased markedly in size between the ages of 13 and 22 years and was similar to changes observed for the zone of low MFA wood. Average MOE for all trees at age 13 was $10.2 \mathrm{GPa}$ and had increased to an average of $12.3 \mathrm{GPa}$ at 22 years [15]. Individual trees at 13 years had average individual tree stiffness values that ranged from 7.8 to $12.2 \mathrm{GPa}$, while for the 22-year-old trees average single tree MOE's ranged from 10.1 to $14.4 \mathrm{GPa}$ [15].

\subsection{The Influence of Age on Wood Quality of Elasticity}

To examine the influence of age on wood quality the proportion of wood meeting specific values for density, MFA and MOE was determined. For the properties examined design values for lumber (11 GPa and $9.7 \mathrm{GPa}$ are used for No. 1 and No. 2 visually graded southern pine lumber respectively) are commonly quoted and were used as thresholds; however, similar values for density and MFA do not exist. Hence thresholds of 650 and $550 \mathrm{~kg} / \mathrm{m}^{3}$ were identified for density, while for MFA 20 and 
$30^{\circ}$ were used. The proportion of wood exceeding the thresholds for each property for P. taeda trees aged 13 and 22 years is reported in Table 2.

Table 2. Fit Proportion of wood meeting thresholds for air-dry density (650 and $550 \mathrm{~kg} / \mathrm{m}^{3}$ ), microfibril angle (MFA) $\left(20\right.$ and $\left.30^{\circ}\right)$ and modulus of elasticity (MOE) (11 and 9.7 GPa) in 13 and 22-year-old P. taeda.

\begin{tabular}{cccccc}
\hline Property & Age (years) & Threshold 1 & Proportion & Threshold 2 & Proportion \\
\hline Air-dry density & 13 & 650 & 21 & 550 & 57 \\
Air-dry density & 22 & 650 & 31 & 550 & 75 \\
MFA & 13 & 20 & 45 & 30 & 91 \\
MFA & 22 & 20 & 77 & 30 & 97 \\
MOE & 13 & 11 & 44 & 9.7 & 58 \\
MOE & 22 & 11 & 74 & 9.7 & 83 \\
\hline
\end{tabular}

\section{Discussion}

Maps depicting within-tree variation of important $P$. taeda wood properties for trees of two different ages (13 and 22 years respectively) were developed using Akima's interpolation method. The maps were used to compare how patterns of variation for air-dry density, MFA and MOE for $P$. taeda trees aged 13 differed from those for trees aged 22. Zones of high density, low MFA and high MOE wood increased markedly in size in maps of the older trees and these changes corresponded to higher average whole-tree density and MOE and lower whole tree MFA for the 22-year-old trees [15]. The changes observed for all properties are consistent with the asymptotic progression of properties associated with full maturity in older trees [1]. For all properties the proportion of wood exceeding the predetermined thresholds increased with age. Possibly the most important difference was the proportion of wood exceeding the design value for No. 2 lumber ( $58 \%$ for trees aged 13 versus $83 \%$ for trees aged 22). Another pronounced difference was the proportion of wood meeting the design value for No. 1 lumber (44\% and 74\% respectively for trees aged 13 and 22 years). It is important to make the distinction here between dynamic MOE values used by SilviScan [6] and the difference between static and dynamic MOE values [28].

This work extends research reported in Schimleck et al. [15] and Mora and Schimleck [16] by utilizing the methods developed in these papers to examine how patterns of $P$. taeda wood properties within plantation-grown trees change between the ages of 13 and 22 years. In addition to the aforementioned work, only Schimleck and Michell [3], in their study of Kraft pulp yield within-tree variation of fifteen Eucalyptus nitens (H.Deane \& Maiden) Maiden (shining gum) trees, utilized NIR spectroscopy for this purpose. While the differentiation of yield levels of the maps was relatively coarse, they generally agreed with maps for MFA and MOE in this study, with the periphery of the trees between 15 and $40 \%$ of tree height having the most desirable properties, i.e., the highest yields and radial and longitudinal trends in properties apparent. A difference between these studies was that Schimleck and Michell [3] obtained spectra from milled wood while in this study we utilized spectra obtained from intact radial strips. The move away from grinding wood samples and directly scanning radial strips represents considerable time savings in terms of sample preparation and analysis and this approach has been adopted in other studies of radial variation in Kraft pulp yield [29].

Mora and Schimleck [16] provide a detailed description of the methodologies they used to develop maps of within-tree variation for air-dry density, MFA and MOE. Three different methods were explored: Akima's interpolation, Universal kriging and semiparametric smoothing. Mora and Schimleck [16] reported that for P. taeda, maps generated by Akima's interpolation method provided good representation of the expected trends in air-dry density and MFA. In addition, they reported that a principal advantage of the Akima's algorithm over the Universal kriging and semiparametric smoothing techniques was that only straightforward procedures were required, and there were no problems concerning computational stability or convergence. Owing to these features only Akima's 
interpolation method was used to provide the maps that were used to compare wood property variation within trees aged 13 and 22 years in this study. If the different methodologies were utilized the wood property maps would demonstrate slightly different patterns of variation; however, the age-related trends reported in this study would still be observed.

For studies of within-tree variation utilizing NIR spectra collected from solid wood the emergence of hyperspectral imaging presents an impressive improvement in the amount of data that can be collected in a given period of time. Recent studies have reported use of the technology to estimate within ring density variation for Pinus pinea L. (stone pine) [30] and variation in density and MFA for Cryptomeria japonica (L.f.) D.Don (Sugi) radial strips [31]. In both studies, the agreement in NIR (hyperspectral) predicted properties and measured data was very good (for [31] SilviScan data was used for calibration). Other studies [32,33] have used hyperspectral images of whole P. radiata disks to develop maps showing variation across the transverse surface for properties such as cellulose, hemicellulose, lignin, galactose, glucose and mannose. The use of hyperspectral scanning systems would allow for separation of calibration data by annual ring as well as within annual rings (i.e., earlywood and latewood), and thus improved models could be developed using these systems. While this study utilized NIR spectroscopy for the provision of data it should be noted that other scanning methods, for example X-ray computed tomography, have recently been used to generate data for mapping the within-tree variation of wood properties [34].

\section{Conclusions}

Maps based on Akima's interpolation method were successfully used to compare wood property (air-dry density, MFA and MOE) variation within P. taeda trees aged 13 and 22 years. Zones of high density, low MFA and high MOE wood increased markedly in size in maps of the older trees. The proportion of wood meeting the visually graded No. 1 (11 GPa) and No. 2 (9.7 GPa) MOE design values for southern pine lumber increased from 44 to $74 \%$ and from 58 to $83 \%$ respectively demonstrating the impact of age on end-product quality. Air-dry density increased from pith to bark at all heights but lacked a significant trend vertically, while radial and longitudinal trends were observed for MFA and MOE. The changes observed are consistent with the asymptotic progression of properties associated with full maturity in older trees.

Author Contributions: L.S. and C.M. conceived and designed the initial study of within-tree variation $[15,16]$. C.M. developed the original maps, while F.A. and J.D. developed the maps utilized in this manuscript. L.S. wrote the original draft of the paper with each of the co-authors contributing to subsequent versions.

Acknowledgments: Support for this work was provided by the Georgia TIP3 program and is gratefully acknowledged. The authors thank International Paper for the provision of wood samples and the UGA Wood Quality Consortium for sample collection and preparation.

Conflicts of Interest: The authors declare no conflict of interest.

\section{References}

1. Burdon, R.D.; Kibblewhite, R.P.; Walker, J.C.F.; Megraw, R.A.; Evans, R.; Cown, D.J. Juvenile versus mature wood: A new concept, orthogonal to corewood versus outerwood, with special reference to Pinus radiata and P. taeda. For. Sci. 2004, 50, 399-415.

2. Evans, R. Rapid measurement of the transverse dimensions of tracheids in radial wood sections from Pinus radiata. Holzforschung 1994, 48, 168-172. [CrossRef]

3. Schimleck, L.R.; Michell, A.J. Determination of within-tree variation of kraft pulp yield using near-infrared spectroscopy. Tappi J. 1998, 81, 229-236.

4. Jones, P.D.; Schimleck, L.R.; Peter, G.F.; Daniels, R.F.; Clark, A. Nondestructive estimation of wood chemical composition of sections of radial wood strips by diffuse reflectance near infrared spectroscopy. Wood Sci. Technol. 2006, 40, 709-720. [CrossRef]

5. Evans, R. A variance approach to the X-ray diffractometric estimation of microfibril angle in wood. Appita J. 1999, 52, 283-289, 294. 
6. Evans, R. Wood stiffness by $x$-ray diffractometry. In Characterization of the Cellulosic Cell Wall; Stokke, D.G., Groom, L., Eds.; Blackwell Publishing: Ames, IA, USA, 2006; pp. 138-146. ISBN 978-0-813-80439-2.

7. Evans, R.; Downes, G.; Menz, D.; Stringer, S. Rapid measurement of variation in tracheid transverse dimensions in a radiata pine tree. Appita J. 1995, 48, 134-138.

8. Evans, R.; Stringer, S.; Kibblewhite, R.P. Variation of microfibril angle, density and fibre orientation in twenty-nine Eucalyptus nitens trees. Appita J. 2000, 53, 450-457.

9. Schimleck, L.R.; Evans, R.; Ilic, J. Estimation of Eucalyptus delegatensis wood properties by near infrared spectroscopy. Can. J. For. Res. 2001, 31, 1671-1675. [CrossRef]

10. Schimleck, L.R.; Evans, R. Estimation of Pinus radiata D. Don tracheid morphological characteristics by near infrared spectroscopy. Holzforschung 2004, 58, 66-73. [CrossRef]

11. Schimleck, L.R.; Evans, R. Estimation of microfibril angle of increment cores by near infrared spectroscopy. IAWA J. 2002a, 23, 225-234. [CrossRef]

12. Schimleck, L.R.; Evans, R. Estimation of wood stiffness of increment cores by near infrared spectroscopy: The development and application of calibrations based on selected cores. IAWA J. 2002b, 23, 217-224. [CrossRef]

13. Schimleck, L.R.; Evans, R. Estimation of air-dry density of increment cores by near infrared spectroscopy. Appita J. 2003, 56, 312-317.

14. Jones, P.D.; Schimleck, L.R.; Peter, G.F.; Daniels, R.F.; Clark, A. Nondestructive estimation of Pinus taeda L. wood properties for samples from a wide range of sites in Georgia. Can. J. For. Res. 2005, 35, 85-92. [CrossRef]

15. Schimleck, L.R.; Mora, C.R.; Jordan, L.; White, D.E.; Courchene, C.E.; Purnell, R.C. Determination of within-tree variation of Pinus taeda wood properties by near infrared spectroscopy. Part 1: Development of multiple height calibrations. Appita J. 2009, 62, 130-136.

16. Mora, C.R.; Schimleck, L.R. Determination of within-tree variation of Pinus taeda wood properties by near infrared spectroscopy. Part 2: Whole-tree wood property maps. Appita J. 2009, 62, 232-238.

17. Jordan, L.; Clark, A.; Schimleck, L.R.; Hall, D.B.; Daniels, R.F. Regional variation in wood specific gravity of planted loblolly pine in the United States. Can. J. For. Res. 2008, 38, 698-710. [CrossRef]

18. Butler, M.A.; Dahlen, J.; Daniels, R.F.; Eberhardt, T.L.; Antony, F. Bending strength and stiffness of loblolly pine lumber from intensively managed stands located on the Georgia Lower Coastal Plain. Eur. J. Wood Prod. 2016, 74, 91-100. [CrossRef]

19. R Core Team. R: A Language and Environment for Statistical Computing; R Foundation for Statistical Computing: Vienna, Austria, 2018.

20. RStudio. RStudio: Integrated Development Environment for R; RStudio: Boston, MA, USA, 2018. Available online: https:/ / www.rstudio.com/ (accessed on 19 April 2018).

21. Akima, H.; Gebhardt, A. Akima: Interpolation of Irregularly and Regularly Spaced Data, R Package Version 0.6-2. 2016. Available online: https:/ /CRAN.R-project.org/package=akima (accessed on 19 April 2018).

22. Wickham, H.; Francois, R. dplyr: A Grammar of Data Manipulation, R Package Version 0.4.3. 2016. Available online: https:/ /CRAN.R-project.org/package=dplyr (accessed on 19 April 2018).

23. Nychka, D.; Furrer, R.; Paige, J.; Sain, S. Fields: Tools for Spatial data, R Package Version 8.10. 2015. Available online: http:/ /CRAN.R-project.org/package=fields (accessed on 19 April 2018).

24. Sarkar, D. Lattice: Multivariate Data Visualization with R; Springer: New York, NY, USA, 2008; ISBN 978-0-387-75968-5.

25. Megraw, R. Wood Quality Factors in Loblolly Pine; TAPPI Press: Atlanta, GA, USA, 1985.

26. Jordan, L.; Daniels, R.F.; Clark, A.; He, R. Multilevel nonlinear mixed-effects models for the modeling of earlywood and latewood microfibril angle. For. Sci. 2005, 51, 357-371.

27. Ying, L.; Kretschmann, D.E.; Bendtsen, B.A. Longitudinal shrinkage in fast-grown loblolly-pine plantation wood. For. Prod. J. 1994, 44, 58-62.

28. Divós, F.; Tanaka, T. Relation between static and dynamic modulus of elasticity of wood. Acta Silv. Lignaria Hung. 2005, 1, 105-110.

29. Downes, G.M.; Meder, R.; Ebdon, N.; Bond, H.; Evans, R.; Joyce, K.; Southerton, S. Radial variation in cellulose content and Kraft pulp yield in Eucalyptus nitens using near-infrared spectral analysis of air-dry wood surfaces. J. Near Infrared Spectrosc. 2010, 18, 147-155. [CrossRef] 
30. Fernandes, A.; Lousada, J.; Morais, J.; Xavier, J.; Pereira, J.; Melo-Pinto, P. Measurement of intra-ring wood density by means of imaging VIS/NIR spectroscopy (hyperspectral imaging). Holzforschung 2013, 67, 59-65. [CrossRef]

31. Ma, T.; Inagaki, T.; Tsuchikawa, S. Calibration of SilviScan data of Cryptomeria japonica wood concerning density and microfibril angles with NIR hyperspectral imaging with high spatial resolution. Holzforschung 2017, 71, 341-347. [CrossRef]

32. Thumm, A.; Riddell, M.; Nanayakkara, B.; Harrington, J.; Meder, R. Near infrared hyperspectral imaging applied to mapping chemical composition in wood samples. J. Near Infrared Spectrosc. 2010, 18, 507-515. [CrossRef]

33. Thumm, A.; Riddell, M.; Nanayakkara, B.; Harrington, J.; Meder, R. Mapping within-stem variation of chemical composition by near infrared hyperspectral imaging. J. Near Infrared Spectrosc. 2016, 24, 605-616. [CrossRef]

34. Longuetaud, F.; Mothe, F.; Fournier, M.; Dlouha, J.; Santenoise, P.; Deleuze, C. Within-stem maps of wood density and water content for characterization of species: A case study on three hardwood and two softwood species. Ann. For. Sci. 2016, 73, 601-614. [CrossRef]

(C) 2018 by the authors. Licensee MDPI, Basel, Switzerland. This article is an open access article distributed under the terms and conditions of the Creative Commons Attribution (CC BY) license (http:/ / creativecommons.org/licenses/by/4.0/). 